\title{
Art Essays and Computer Letters
}

\section{Wendy Holmes}

The University of Rhode Island

$O_{\text {ne of the primary goals of the Introduction to Art course that I teach }}$ every semester is to develop students' skills in interpreting works of visual art by requiring them to write brief interpretive essays on paintings that are new to them. Although many of the students (mostly freshmen) have experience in isolating themes, developing their own opinions, and supporting their ideas by specific references or quotations from literary texts, almost none have previous experience with interpreting paintings. It is difficult for most of them to transfer general principles and skills from writing about stories or poems to writing about paintings, and it is particularly difficult for many to absorb the idea that, although their essays should include descriptive passages, interpreting a painting is not simply describing the figures, things, and places that are represented in it.

Since the class must be taught in a large auditorium, to between one hundred and fifty to two hundred students (with no discussion section), there are few opportunities for general interchange or the oral interpretation of paintings, so the essays provide rare occasions for students to apply and synthesize information discussed in the course text and the lectures. Students are required to write essays as part of the two five-week exams and they have the option (which most of them do not take) of writing an essay as part of their final. The format for the two essays is provided on the course syllabus as follows:

From To Improve the Academy: Resources for Student, Faculty, and Institutional Development, Vol. 7. Edited by J. Kurfiss, L. Hilsen, S. Kahn, M.D. Sorcinelli, and R. Tiberius. POD/New Forums Press, 1988. 


\section{ESSAY I}

The works shown (slides of Christina's World by Andrew Wyeth and The Scream by Edward Munch, for example) represent similar subjects but express different themes, feelings, or ideas. Compare and contrast what is expressed in each painting, taking account of a. b. and c. below as support and explanation for your opinions.

a. What is represented and how?

b. What visual elements are employed and how are they organized?

c. What media and techniques are used?

\section{ESSAY II}

Same as above (slides of Kathe Kollwitz's The People and Giorgio de Chirico's The Mystery and Melancholy of a Street - artists discussed in the text and lectures), plus:

d. Which 19 th or 20 th-century styles do the paintings belong to?

e. Which other paintings or artists or styles have interesting

relationships to these two examples?

Essay I follows a series of exercises, lectures, and readings on the organization of images, such "visual elements" as line, color, shape, and texture, and a survey of visual media and techniques. The different aspects of painting that may be considered under "a" through " $c$ " and how each may relate to the overall theme or idea of a painting have been fully discussed, so the questions here serve as reminders. Essay II, which comes at the conclusion of a study of prominent styles and artists from the 1860s to the 1960 s, builds on the established format. It is emphasized that the basis for the first interpretation is careful observation and analysis of the internal features and organization of the paintings, while the second interpretation is based on background information, as well as what meets the eye directly.

\section{The Problem}

My goal of developing interpretive skills which will be applicable to a wide variety of paintings not specifically dealt with in this course is largely thwarted by the size of the class. I am committed to two two-week periods of intense grading each semester and I am able to make fairly extensive comments on each essay - which the students seem to appreciate. However, even the student who is able to make adjustments to the second 
essay, based on my comments on the first, may make an entirely different set of mistakes and have no sense of development or improvement. In order to develop skills and correct mistakes, students should write at least four or five essays during the semester; some of these should be identical in format. Without making myself a grading machine, I cannot take the time to read and assess this many essays in my usual manner.

\section{Method}

With the ultimate aim of assigning more essays and taking less time to grade them, therefore, I proposed the following experiment in the context of the classroom research group sponsored by URI's Instructional Development Program. I wanted to compare (1) the quality of student essays, (2) students' attitudes toward how their essays were graded, and (3) the amount of time spent grading essays, when half of the essays were assessed in my usual way, with notes in the margins, questions, underlinings, etc., and the others were evaluated by means of computer-printed letters which sketched out their principal strengths and weaknesses.

After grading the first group of essays in my usual way, I proposed the compilation of a glossary of numbered comments consisting of paragraphs and sentences frequently applied to the first batch of essays. In grading the second group, I would simply write the numbers of appropriate comments on the class roster, leaving it to my (highly responsible, mature) undergraduate assistant to write "Dear X," print out the pertinent paragraphs, and staple the letter to the exam for my signature. I proposed keeping track of the time that it took me to grade each group of essays, the time it took to compile the bank of comments, and the time it took my assistant to print the letters. After each exam, I would also solicit student feedback on the value of my commentary by means of a short questionnaire, asking (1) Did the comments indicate what was good about your essay? (2) Did the comments indicate what was wrong with your essay? (3) Would my comments on this essay enable you to now write a better essay on the same paintings? (4) Would my comments on this essay enable you to write a better essay of the same type on different paintings? After students had received one set of "normal" comments and one computergenerated letter, I would ask: (5) Which kind of feedback do you prefer? Finally, I would keep track of students' grades on the two essays. 


\section{Description of Comments}

For the first essay, I developed a bank of comments very similar to the comments I write on student papers. These consisted of (1) ten fairly long paragraphs having the titles of EXCELLENT, EXCELLENT BUT TOO GENERAL, VERY GOOD BUT, GOOD BUT NON-SPECIFIC DESCRIPTION, DESCRIPTION NOT RELATED TO INTERPRETATION, TOO DESCRIPTIVE, NOT COMPARATIVE, RIGHT IDEA/ UNINSPIRED, ABBREVIATED/SUPERFICIAL, and STORY, corresponding to the paragraphs that I normally write at the bottom of essays, summarizing the main problems of the essay and providing an overall rationale for the grade; (2) about ten short specific comments on the particular paintings they were writing on, such as: "I like your discussion of the stylized landscape in The Scream." "Look at Christina's position carefully when I show the slide again. Doesn't it seem awkward to you? Is this a comfortable position in which to sit back and enjoy the beauties of nature? Is "nature" represented here as lush and beautiful?" These correspond to brief phrases, questions, underlinings, and question marks that I normally insert in the text of the essays. Additionally, there were (3) such short statements as "I like the fact that you compare the two paintings very directly throughout your essay, bringing out the overall ideas or themes of each in relation to the other." and "Remember that you're being asked to compare the two paintings. This almost reads like two separate interpretive essays." (4) There were five comments on the use and misuse of terminology such as: "Check chiaroscuro in Hobbs. This term doesn't apply to any value contrast, only to light to dark shading used to suggest the fall of light on three-dimensional objects." Finally, (5) there were comments on writing style, grammar, and sentence and paragraph structure, ranging from a seventeen-line comment on general organization (see Appendix) to the one-liner: "You write very well! I get a vivid image of the paintings from your descriptions.

The comments on the second essay were similar, with the addition of (6) a category of comments on the historical context, e.g., Post-Impressionism, Expressionism, Surrealism (see appendix), but additionally complicated by the fact that students had the option of writing on either of the two paintings shown or of comparing them.

\section{Problems of Implementation}

Many of the problems I ran into had nothing whatsoever to do with idea of my project and everything to do with the fact that my student as- 
sistant and I were new computer users dealing with an imperfect and quirky system. I stopped keeping track of our time when it became evident that we were spending ages on this project, partly due to mechanical difficulties and user inexperience.

It should have been relatively simple to establish a glossary of named or numbered comments as the components of individualized letters, which to save time, could be printed out by someone other than the instructor. In future, I think it will be easy to do this. This time, however, it took two-and-a-half weeks before the first group of essays werc returned and an unprecedented three-and-a-half weeks to return the second essay.

The second set of problems had to do with the nature of the comments themselves. I found these very difficult to write, in spite of the fact that I normally scribble away on student papers with great speed and fluidity. I fiddled with my bank of comments for an inordinately long time because I didn't like them, in spite of the fact that they were a fairly close facsimilie of the range and type of comments I've been scrawling on student essays for the last fifteen years. Faced with systematizing the "normal" range of comments I make on essays, I realized how unsystematic they were and found that the process of preparing a glossary of comments precipitated a wholesale analysis of intentions and effects, changing my focus from efficient delivery of feedback to students to its analysis. Although other experienced essay graders might not discover the same sorts of flaws in the substance of their comments as I did, I believe that the process of gathering and grouping leads naturally to analysis, which is more fundamental and difficult than any question of whether or not to do computer letters and which certainly complicates and defers this question.

\section{Results}

As already noted, I stopped counting the hours spent on compiling the banks of comments used to generate the computerized grading letters. It took a long time, much longer, this first time around, than it would have taken to grade and write on the essays in my usual fashion. I did, however, ask students to complete the five-item reaction questionnaire after returning each of the essays. It was clear that students much preferred the handwritten comments. After the second essay exam, by which time each student had experienced both modes of commentary, two-thirds indicated a preference for handwritten comments while less than a quarter preferred the computerized letter. In contrast, there were no differences in students' ratings of how useful the two types of comments 
were after the first exam, except that the handwritten comments were better indicators of what was good about their essays. Whatever student preferences after the second exam, their ratings of the usefulness of both types of comments were high (ranging from a $72 \%$ indication that the comments would help improve subsequent essays on different paintings to the $88 \%$ who thought that the comments indicated what was good about their essay), with the computerized comments rated as useful by a slightly higher percentage of students than the handwritten comments.

Finally, the grades on Essay II averaged about half a point higher (on a 10-point scale) than grades on the first essay, which is usual in my experience. The mode of commenting on the first essay did not differentially affect scores on the second, so, although students were not enthusiastic about the computer letters, they were evidently helpful.

\section{Discussion}

The principle benefits of the classroom research had less to do with computer letters versus "normal" handwritten comments on essays than with the analysis of grading practices which resulted. Having a bank of comments that were reasonable approximations of what I normally write on student essays was very revealing. I already knew, for example, that I tended to focus on what was wrong with the essays and gloss over the positive features with the blanket statement, "You make some good points about the two paintings, but..." However, I did not realize how extreme my cataloging of problems was or how dismaying this was for students. In relation to my computer letters on the first essay, this was graphically illustrated when I saw that some students received two pages of singlespaced negative commentary on their essays. Similarly, I always wrote least on the excellent essays. With the help of the faculty classroom research group, I came to realize that I was reading for problems and that the things that most students were doing right (e.g., operating on an appropriate interpretive level) became invisible to me as I was grading. Traditional and computer letter feedback on the first essay was uniformly negative and the grades were (as usual) low, in spite of the fact that I had the impression that this class's essays were rather better than the norm; on the day that I handed them back, students were vociferously disgruntled. Because the essays were, on the whole, good, I later realized that I had unconsciously raised my standards.

I worked on developing a range of positive comments for the second essay and I was careful to include positive reinforcement in the handwritten notes, which, I believe, improved morale and enabled students to bet- 
ter accept my discussions of their problems. In writing comments on the second essay, I fell into the habit of using the format "The good points of this essay are:" and listing them by number, then "The not-so-good points are:" and listing these. In future experiments with computer feedback, I shall be sure to use the same format for my notes on exams and the computer printout.

Students in large classes, who have little individual contact with instructors, will probably continue to prefer the human touch of handwritten notes and individualized responses to computer letters composed of stock paragraphs and phrases. From my point of view, however, it is worth continuing classroom research with essays and computers for several reasons. I have already discussed the analytic value of compiling and categorizing frequently repeated messages to students. Many of my comments are, in fact, standardized, whether or not they are handwritten. By preparing mini-essays on common problems, I can often provide students with more complete and better-illustrated explanations of what these problems are and how to avoid them, and, at the same time, free myself of some of the drudgery of repetition. The computer letter will eventually enable me to make more comments and assign more essays. I also forsee that I will be able to use the glossaries from previous exams in preparatory exercises or special essay-writing help sessions. Too, it would be interesting to test the objectivity of grading essays by grading them twice, with the same glossary of comments, or comparing the glossary selections of different graders. Assuming that it is easier to select appropriate comments than to compose them, some modification of the computer-glossary idea might be especially useful in preparing graduate student teaching assistants to deal with the piles of essays and papers to be evaluated which await them.

Apart from large class teaching or self-analysis, devising banks or glossaries of comments for response to students' written assignments is probably unnecessary or inappropriate. I would suggest that others wishing to experiment with computer letter feedback start writing out, developing, and categorizing their comments at least one semester before implementing the project. The computer letters may save time eventually, but it will make grading essays more time-consuming the first time around, and, I suspect, the second time as well. 


\section{Appendix}

\section{Samples of Computer Letters}

\section{EXCELLENT ANSWER, ESSAY I}

\section{Dear Mary,}

This is an excellent essay answer in which description is used well to develop and illustrate your interpretive points. The comparisons you make are interesting and convincing. Some of the following points are "quibbles" rather than real problems in your essay (keep them in mind so that they don't become problems in the other essays you write).

I realize that it is difficult to produce an organized essay in the short time period of one class, however, the lack of organization in your essay is diluting the strength of the good descriptive and comparative points you make! Use paragraph structure to help in dealing with the question in an orderly way. For example, start off with a general interpretive statement of comparison between the two paintings. Even if it is very short, let this be your first paragraph. Go on to support and explain what you say in the first pargaraph by describing and comparing the styles of representation in the two paintings. Here, deal with facial expressions, poses, relationships of figures, locations of figures in the picture space, relationships between figures and environment - anything that relates to the paintings as representations of the visible world. Let this be your second paragraph. Next, describe and compare the visual elements (colors, lines, shapes, textures, and their relationships) which best support your interpretive points in another paragraph. If you have an interpretive conclusion or summary, make this your final paragraph. This sort of paragraph structure will serve to guide your reader, signaling when you are finished with one category of concerns and are ready to turn to the next.

Use the worksheet provided as a sort of outline of your main points along the lines suggested above. Don't start writing your essay until you have settled on your main points on the worksheet.

Sincerely yours,

\section{GOOD ANSWER - PROBLEM WITH DESCRIPTION, ESSAY I}

This is a good essay answer, with a clear interpretive thesis and some good descriptive support. Be careful, however, to make your descriptions specific, for example, don't just say that Christina's position is awkward, describe how it is - say that her body is twisted from the waist, supported 
by thin out-stretched arms as she leans toward the house on the horizon. Or, in discussing the visual elements, don't just say that Munch uses highly saturated colors (some are highly saturated, some aren't), but say where, and say how these interact with other colors - for example, the intense red of the sky is in strong contrast to the dull colors used elsewhere in the painting; it casts a fiery glow over the swirling landscape and screaming figure below. Of course, I may know what you mean when you refer generally to some aspect of the image or the visual elements, but, in order to understand your interpretation fully, I must have more information about what it is based upon. I must have more information about how you see the paintings. Although it may be better to omit technical terms than to overuse them, the technical vocabulary introduced in Chapter 2 of Hobbs is intended to serve as a tool for exact description. Use the correct terms, when appropriate, and be sure to study terminology before the multiple choice part of the first exam.

\section{EXCELLENT, ESSAY II}

This is an excellent essay answer in which description is well used to develop and illustrate your interpretive points. What you say is interesting and convincing. The new aspects of the questions are well integrated with the rest of your statements.

I appreciate your specific descriptions of the facial expressions and postures of the figures, but don't forget about the space they occupy - the broad white margins and the block of shading above the heads - which also contributes to the overall mood or idea.

The following points are mostly "quibbles" rather than serious problems (I have to include more than general praise, especially since I've taken so long in grading) but take care not to let them become problems on your final.

The other works and/or artists you mention are potentially good comparisons but your development is sketchy. You must describe and discuss other works fully enough to establish what the basis of comparison with The People is, how they are similiar to The People and how they are different. The whole point of comparing is to enable you to say more about this particular drawing by placing it in a comparative context. The list, SPECIFIC WORKS TO REMEMBER FOR EXAM II AND FINAL, is a good source of specific comparisons. Look carefully at these paintings, most of which are reproduced in your text book, as well as memorizing the dates and titles.

For future reference, remember that both Hobbs and I simplified some styles and relationships for purposes of presenting a clear introduc- 
tion to a very complex period, so don't be surprised if you discover that the classification of artists and the differentiation among styles is more problematic than was indicated. We must start to make sense of any period or any subject by making some grand generalizations which are later called into question; your sense-making is just fine at this stage.

\section{ADEQUATE ANSWER, ESSAY II}

This is a nice general interpretation of The People supported by a.b.c. sorts of considerations. The kinds of observations you make about the drawing are always relevant in interpretation, so this is a strength of your essay.

You make some good points about the space and location of images, but don't forget to describe (some of) the facial expressions you mention in some detail.

You correctly identify Kathe Kollwitz as a German Expressionist (just "Expressionist" is O.K. but less precise) - good. However, you must say more about this style. Describe the main concerns and characteristics of the movement and the range of its productions. Be sure to say what the German Expressionist characteristics of The People are and mention a couple of other examples.

The other works and/or artists you mention are potentially good comparisons but your development is sketchy. You must describe and discuss other works fully enough to establish what the basis of comparison with The People is, how they are similiar to The People and how they are different. The whole point of comparing is to enable you to say more about this particular drawing by placing it in a comparative context. The list, SPECIFIC WORKS TO REMEMBER FOR EXAM II AND FINAL, is a good source of specific comparisons. Look carefully at these paintings, most of which are reproduced in your text book, as well as memorizing the dates and titles. 